\title{
PHARMACOLOGICAL EVALUATION OF PIRACETAM AND VANADYL SULFATE ON EXPERIMENTALLY INDUCED CEREBRAL ISCHEMIA IN RATS
}

\author{
BANAPPA S. UNGER, HIMASAILA M.* \\ Department of Pharmacology, KLE University's College of Pharmacy, KLE University JNMC campus, Nehru Nagar, Belgaum 590010. \\ Karnataka State, India \\ Email: himachaithu26@gmail.com
}

Received: 16 May 2016 Revised and Accepted: 22 Jul 2016

\begin{abstract}
Objective: The aim of present study was designed to evaluate the combinatorial effect of piracetam and vanadyl sulfate on experimentally induced global cerebral ischemia in rats.

Methods: Piracetam (600 mg/kg, p. o.) and vanadyl sulfate $(22.4 \mathrm{mg} / \mathrm{kg}$, p. o.) were administered individually and also in combination before the induction of ischemia. Cerebral ischemia was induced by bilateral carotid artery (BCA) occlusion for 30 min followed by reperfusion 60 min.

Results: The antioxidant and non-antioxidant enzymatic levels were estimated along with histopathological studies. The concomitant pretreated group showed a more significant decrease in lipid peroxidation (LPO) and increased in the superoxide dismutase (SOD), catalase (CAT), glutathione (GSH) and total thiol levels as compared to ischemic reperfusion group. Histopathological damage was significantly reduced in drug treated groups as compared to ischemia-reperfusion group.
\end{abstract}

Conclusion: The findings of the present study suggest that pretreatment with piracetam and vanadyl sulfate in combination prevents the ischemiareperfusion injury and prevented oxidative tissue damage as shown by decreased lipid peroxides, restored the antioxidant levels, histological changes such as infarct area, inflammatory changes, and edema.

Keywords: Cerebral ischemia, Piracetam, Vanadyl sulfate, Antioxidants

(C) 2016 The Authors. Published by Innovare Academic Sciences Pvt Ltd. This is an open access article under the CC BY license (http://creativecommons. org/licenses/by/4. 0/) DOI: http://dx.doi.org/10.22159/ijpps.2016v8i9.12875

\section{INTRODUCTION}

Cerebrovascular diseases include some of the most common devastating disorders such as ischemic stroke, hemorrhagic stroke, cerebrovascular anomalies, etc. They cause two lakhs deaths each year and are a major cause of disability [1]. Stroke has been ranked third most common cause of death worldwide. Furthermore, stroke is the leading cause of adult disability with approximately one-third of patients who survive 6 mo are dependent on others [2]. India shows a crude stroke prevalence rate of about 203 per 100,000 population above $20 \mathrm{y}$ of age, amounting to a total of about 1 million cases. 6 The male-to-female ratio was estimated to be 1.7. Most studies carried out in India show that about $10 \%$ to $15 \%$ of strokes occur in the population below $40 \mathrm{y}$, which is a higher proportion compared with other countries [3, 4]. However, it was estimated that stroke represented $1.2 \%$ of the total deaths in the country when all ages were included. The proportion of stroke death is increased with age, and in the oldest group ( $>70 \mathrm{y}$ of age) stroke contributed to $2.4 \%$ of all deaths [5]. According to the World Health Organization, 15 million people suffer stroke worldwide each year. Of these, 5 million die and another 5 million are permanently disabled.

The concept of neuroprotection is derived from the studies of ischemic brain injury. It has been well documented that abrupt deprivation of oxygen and glucose to neuronal tissues elicits a series of pathological cascades, leading to the spread of neuronal death. Of the numerous pathways identified, excessive activation of glutamate receptors, accumulation of intracellular calcium ions, abnormal recruitment of inflammatory cells, excessive production of free radicals and initiation of pathological apoptosis are believed to play critical roles in ischemic damage, especially in the penumbral zone. Thus, it is logical to suggest that if one is able to interrupt the propagation of these cascades, at least part of the brain tissue can be protected [6]. Brain ischemia or cerebral ischemia is a condition which leads to alterations in brain metabolism, reduction in metabolic rates and energy crisis where the brain cannot perform aerobic metabolism due to lack of oxygen supply $[7,8]$.
Though a large number of therapeutic agents like thrombolytics, NMDA receptor antagonists, calcium channel blockers, antioxidants, sodium-channel and potassium channel openers, glutamate antagonists, magnesium sulphate, glycine antagonists, GABAergic compounds (such as clomethiazole), piracetam, growth factors (such as basic fibroblast growth factor), free radical scavengers(such as tirilazad), and anti-inflammatory compounds (such as enlimomab). Have been used or being evaluated, there remains a large gap between the benefits by these agents and properties an ideal drug for stroke should offer [9].

Piracetam is the derivative of gamma amino butyric acid (GABA), widely used in clinical practice as nootropic agent and also used in the treatment of brain dysfunction. It influences neuronal and vascular functions and influences cognitive function without acting as a sedative or a stimulant. Piracetam has been reported to have neuroprotective, anticonvulsant, and neuroplasticity. It also restores dopamine release impaired by hypoxia and improved cortical neuronal responsiveness [10]. Vanadyl sulfate has an ameliorating effect on oxidative stress via its antioxidant property and has antidiabetic activity [11]. Vanadyl sulfate involves in the activation of phosphatidylinositol 3-kinase in brain ischemia. Vanadyl sulfate is responsible for insulin-like activity and can mimic the action of insulin through alternative signaling pathways [12]. The cardioprotective activity of vanadyl sulfate has been reported [13]. The aim of present study was to explore whether concomitant pretreatment with piracetam and vanadyl sulfate exerts better effect than piracetam and vanadyl sulfate alone.

\section{MATERIALS AND METHODS}

\section{Animals}

Male wistar rats weighing between 200-250 gm, were procured from Sri Venkateswara enterprises Bangalore. They were housed in standard laboratory condition with $12 \mathrm{~h}$ light/dark cycle. The animals were fed with standard pelleted diet and water ad libitum. After seven days of acclimatization period, they were randomly 
selected for different experimental groups. All the experiment was carried out according to CPCSEA guidelines. Ethical clearance was obtained from Institutional Animal Ethics Committee (IAEC Reg. No. 221/CPCSEA) Belgaum, before conducting the experiment.

\section{Drugs and chemicals}

Piracetam was a generous gift from strides micro labs, Banglore; vanadyl sulfate was a gift sample from Omkar specialty chemicals, Thane. ellman's reagent, trichloroacetic acid (TCA), 2-thiobarbituric acid (TBA). All other chemicals were of the highest purity commercially available.

\section{Dose selection}

Piracetam at the dose of $600 \mathrm{mg} / \mathrm{kg}$ [14] was dissolved in distilled water and was administered orally $2 \mathrm{~h}$ and $24 \mathrm{~h}$ before occlusion. Vanadyl sulphate at the dose of $22.4 \mathrm{mg} / \mathrm{kg}$ [15] was dissolved in distilled water and was administered orally $2 \mathrm{~h}$ and $24 \mathrm{~h}$ before occlusion.

\section{Experimental protocol for cerebral ischemia}

Cerebral ischemia was induced by bilateral carotid artery occlusion; a global ischemia model was carried out in the present study. The male wistar rats $(200-250 \mathrm{~g})$ were divided into six groups of 8 animals each. Group-I: Normal saline $(10 \mathrm{ml} / \mathrm{kg}, \mathrm{p} . \mathrm{o})$, no ischemia, Group-II-Ischemia (NS+I): Normal saline $(10 \mathrm{ml} / \mathrm{kg}, \mathrm{p} . \mathrm{o})+$ bilateral carotid artery occlusion for $30 \mathrm{~min}$, Group III-Ischemia reperfusion(IR): Normal saline $(10 \mathrm{ml} / \mathrm{kg}$, p. o)+bilateral carotid artery occlusion for $30 \mathrm{~min}$ followed by reperfusion for $60 \mathrm{~min}$. Group IV-(IR+P): Piracetam (600 mg/kg, p. o)+bilateral carotid artery occlusion for $30 \mathrm{~min}$ followed by reperfusion for $60 \mathrm{~min}$. Group V-(IR+V): Vanadyl sulfate $(22.4 \mathrm{mg} / \mathrm{kg}$, p. o)+bilateral carotid artery occlusion for $30 \mathrm{~min}$ followed by reperfusion for $60 \mathrm{~min}$. Group $\mathrm{VI}-(\mathrm{IR}+\mathrm{P}+\mathrm{V})$ : piracetam $(600 \mathrm{mg} / \mathrm{kg}, \mathrm{p} . \mathrm{o})$ and vanadyl sulfate $(22.4$ $\mathrm{mg} / \mathrm{kg}$. p. o)+bilateral carotid artery occlusion for $30 \mathrm{~min}$ followed by reperfusion for $60 \mathrm{~min}$. Group I serves as Control. Group III serves as ischemia-reperfusion (disease control). Animals of group IV were pretreated with piracetam $24 \mathrm{~h}$ and $2 \mathrm{~h}$ before occlusion. Animals of group $\mathrm{V}$ were pretreated with vanadyl sulfate $24 \mathrm{~h}$ and $2 \mathrm{~h}$ before occlusion. Animals of group VI were pretreated with both drugs (piracetam and vanadyl sulfate) $24 \mathrm{~h}$ and $2 \mathrm{~h}$ before occlusion.

\section{Induction of ischemia}

The animals of group II to VI were subjected to bilateral carotid artery occlusion [16] under ketamine anesthesia ( $45 \mathrm{mg} / \mathrm{kg}$, i. p.). Animals were placed on the back both carotid arteries were exposed and occluded by atraumatic clamps. The temperature was maintained around $37 \pm 0.5{ }^{\circ} \mathrm{C}$ throughout the surgical procedure and artificial ventilation $(95 \% 02$ and $5 \%$ CO2) provided with an artificial respirator.

\section{Preparation of post-mitochondrial supernatant}

The animals were sacrificed by cervical decapitation. The brain was removed by keeping a rat on ice bar and washed in cooled $0.9 \%$ saline, kept on ice and subsequently blotted on filter paper, then weighed and homogenized in cold phosphate buffer $(0.1 \mathrm{M}, \mathrm{pH} 7.4)$. The homogenates were centrifuged at $10000 \mathrm{rpm}$ for $10 \mathrm{~min}$ at $4{ }^{\circ} \mathrm{C}$, and post-mitochondrial supernatant (PMS) was used for the estimation of lipid peroxides (LPO), reduced glutathione (GSH), superoxide dismutase (SOD), catalase (CAT), Total thiols (TT) and Total protein.

\section{Biochemical estimation}

\section{Lipid peroxidation (LPO)}

Thiobarbituric acid reactive substances (TBARS) in the homogenate were estimated by the method of Prabhakar et al.[17]. Briefly, the $0.5 \mathrm{ml}$ of $10 \%$ homogenate was incubated with $15 \%$ TCA, $0.375 \% \mathrm{TBA}$ and $5 \mathrm{~N} \mathrm{HCl}$ at $95^{\circ} \mathrm{C}$ for $15 \mathrm{~min}$, the mixture was cooled, centrifuged and the absorbance of the supernatant measured at $512 \mathrm{~nm}$ against appropriate blank. The amount of lipid peroxidation was determined expressed as TBARS nmoles/mg of protein.

\section{Superoxide dismutase}

SOD assay was carried out by the pyrogallol autoxidation method [18]. The reaction was initiated by $100 \mu \mathrm{l}$ of freshly prepared 2.6 mmol pyrogallol solution in tris buffer $(0.05 \mathrm{M})$ to attain a final concentration in the assay mixture. The absorbance was recorded at $420 \mathrm{~nm}$ for $2 \mathrm{~min}$ from $1 \mathrm{~min} 30 \mathrm{sec}$ to $3 \mathrm{~min} 30 \mathrm{sec}$.

\section{Catalase (CAT)}

Catalase activity was assayed by the method of Claiborne [19]. Briefly, the assay mixture consisted of $1.95 \mathrm{ml}$ phosphate buffer $(0.05 \mathrm{M}, \mathrm{pH} 7.0), 1.0 \mathrm{ml}$ hydrogen peroxide $(0.019 \mathrm{M})$, and $0.05 \mathrm{ml}$ homogenate $(10 \% \mathrm{w} / \mathrm{v})$ in a total volume of $3.0 \mathrm{ml}$. Changes in absorbance were recorded at $240 \mathrm{~nm}$. Catalase activity was calculated in terms of $\mathrm{nM} \mathrm{H}_{2} \mathrm{O}_{2}$ consumed $/ \mathrm{min} / \mathrm{mg}$ protein.

\section{Glutathione (GSH)}

GSH was estimated in various tissues by the method of Sedlak and Lindsay [20]. Briefly, 5\% tissue homogenate were prepared in 20 mmol EDTA, pH 4.7 and $100 \mu \mathrm{l}$ of the homogenate or pure GSH was added to $0.2 \mathrm{M}$ Tris-EDTA buffer $(1.0 \mathrm{ml}, \mathrm{pH} 8.2)$ and $20 \mathrm{mmol}$ EDTA, pH $4.7(0.9 \mathrm{ml})$ followed by $20 \mu \mathrm{l}$ of Ellman's reagent (10 $\mathrm{mmol} / \mathrm{l}$ DTNB in methanol). After $30 \mathrm{~min}$ of incubation at room temperature samples were centrifuged and take absorbance at 412 $\mathrm{nm}$.

\section{Total thiols}

This assay is based on the principle of formation of relatively stable yellow colour by sulfhydryl groups with DTNB. Briefly, $0.2 \mathrm{ml}$ of brain homogenate was mixed with phosphate buffer ( $\mathrm{pH} 8$ ), $40 \mu \mathrm{l}$ of $10 \mathrm{mmol}$ DTNB and $3.16 \mathrm{ml}$ of methanol. This mixture was incubated for $10 \mathrm{~min}$ and the absorbance was measured at $412 \mathrm{~nm}$ against appropriate blanks. The total thiol content was calculated by using $\varepsilon=13.6 \times 10[31] \mathrm{cm}^{-1} \mathrm{M}^{-1}[20]$.

\section{Total protein}

Protein concentration in all samples was determined by the method of Lowry et al. [21].

\section{Histopathology}

The brains from control and experimental groups were fixed with $10 \%$ formalin and embedded in paraffin wax and cut into a longitudinal section of $5 \mu$ thickness. The sections were stained with hemotoxylin and eosin dye for histopathological observation.

\section{Statistical analysis}

Results were expressed as mean \pm SEM. The data was analyzed by using one-way analysis of variance (ANOVA) followed by Dunnett's multiple comparison test. A value of $\mathrm{p}<0.05$ was considered as statistically significant.

\section{RESULTS}

The results in table 1 showed that the LPO levels exhibited significant increase and all other enzymatic and non-enzymatic parameters (SOD, CAT, GSH and Total thiols) showed a significant decrease in the bilateral carotid artery occlusion (BCA) ischemic group $(\mathrm{NS}+\mathrm{I})$. These levels were further increased in ischemiareperfusion (IR) group when compared to control. Piracetam and vanadyl sulfate alone pretreated groups showed significantly $(p<0.05)$ decrease in LPO level and significant $(p<0.05)$ increase in SOD, GSH, CAT, Total thiol levels. Pretreatment with a combination of piracetam and vanadyl sulfate showed very significantly $(p<0.005)$ decrease and increase in SOD, GSH, CAT, Total thiol levels when compared to ischemia-reperfusion group and when compared to the treated groups alone.

\section{Histopathology}

No change was found in histo-architecture of the brain in control group fig. 1. Bilateral carotid artery occlusion induced cerebral ischemia in rats showed marked cerebral edema, moderate cerebral congestion, neuronal vacuolization, mild neutrophilic Infiltration fig. 1(2). Ischemia followed by reperfusion group showed moderate 
cerebral edema, marked cerebral congestion, moderate neuronal vacuolization and mild neutrophilic infiltration fig. 1(3) Pretreatment with piracetam showed mild cerebral edema, cerebral congestion and mild neutrophilic infiltration fig. 1(4). Pretreatment with vanadyl sulfate showed moderate cerebral edema, cerebral congestion and mild neutrophilic infiltration fig. 1(5). Pretreatment with piracetam and vanadyl sulfate showed mild cerebral edema, cerebral congestion and focal neutrophilic infiltration fig. 1(6).

Table 1: Effect of piracetam and vanadyl sulfate on lipid peroxide, superoxide dismutase, glutathione, catalase and total thiols

\begin{tabular}{|c|c|c|c|c|c|c|}
\hline $\begin{array}{l}\text { Group } \\
\text { No } \\
\end{array}$ & Treatment & $\begin{array}{l}\text { LPO (nmol/mg } \\
\text { protein) }\end{array}$ & SOD (U/ml) & $\begin{array}{l}\text { GSH (nmol/mg } \\
\text { protein) }\end{array}$ & $\begin{array}{l}\text { CAT }(\mathrm{U} / \mathrm{mg} \\
\text { protein) }\end{array}$ & $\begin{array}{l}\text { Total thiols } \\
\text { ( } \mu \mathrm{mol} / \mathrm{mg} \text { protein) }\end{array}$ \\
\hline 1 & Control & $19.46 \pm 1.019$ & $195.4 \pm 4.834$ & $11.59 \pm 1.119$ & $0.235 \pm 0.0243$ & $24.11 \pm 2.747$ \\
\hline 2 & $\mathrm{NS}+\mathrm{I}$ & $29.04 \pm 2.628^{\#}$ & $154.3 \pm 7.096^{\#}$ & $7.140 \pm 0.5401^{\#}$ & $0.0132 \pm 0.0022^{\#}$ & $11.49 \pm 1.146^{\#}$ \\
\hline 3 & IR & $35.69 \pm 3.656^{\# \#}$ & $143.8 \pm 4.70^{\# \#}$ & $3.420 \pm 0.3553^{\# \#}$ & $0.0103 \pm 0.0012^{\# \#}$ & $8.965 \pm 1.008^{\# \#}$ \\
\hline 4 & $P(600 \mathrm{mg} / \mathrm{kg})+\mathrm{IR}$ & $22.07 \pm 2.807 *$ & $178.1 \pm 3.60^{* *}$ & $8.827 \pm 0.572 * *$ & $0.07533 \pm 0.0053^{* *}$ & $17.77 \pm 2.147^{* *}$ \\
\hline 5 & $\mathrm{~V}(22.4 \mathrm{mg} / \mathrm{kg})+\mathrm{IR}$ & $22.75 \pm 3.407^{*}$ & $162.5 \pm 5.466^{*}$ & $7.895 \pm 0.8057^{*}$ & $0.05067 \pm 0.003^{*}$ & $14.75 \pm 1.501^{*}$ \\
\hline 6 & $\begin{array}{l}\mathrm{IR}+\mathrm{P}(600 \\
\mathrm{mg} / \mathrm{kg})+\mathrm{V}(22.4 \\
\mathrm{mg} / \mathrm{kg})+\mathrm{IR}\end{array}$ & $21.23 \pm 0.7094^{* *}$ & $185.9 \pm 4.786^{* *}$ & $10.64 \pm 1.177^{* *}$ & $0.1408 \pm 0.00579^{* *}$ & $20.14 \pm 2.024 * *$ \\
\hline
\end{tabular}

Values are mean \pm SEM: $n=8$, one way anova followed by Dunnett's multiple comparison test: \#p<0.001, \#\#p<0.001 when compared to control, ${ }^{* *} \mathrm{p}<0.005,{ }^{*} \mathrm{p}<0.05$ when compared to IR group.
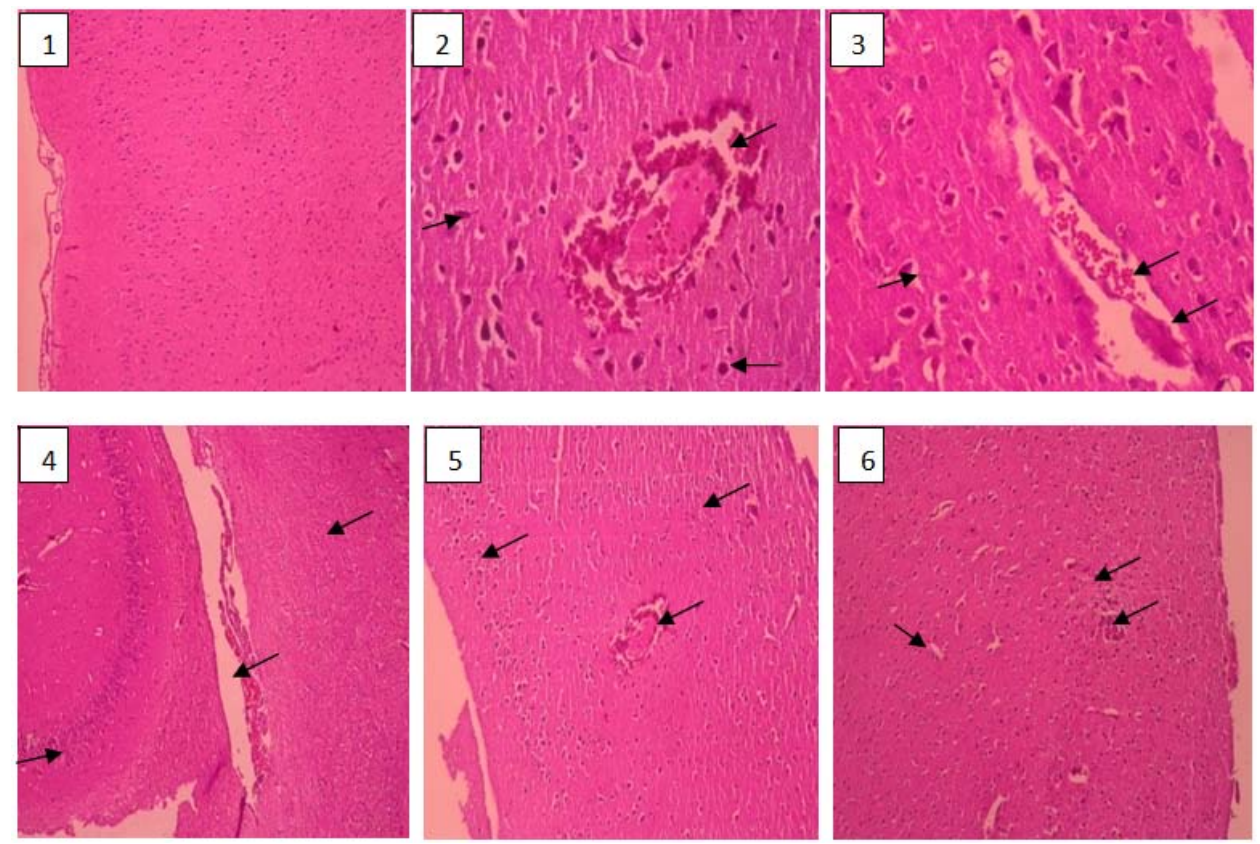

Fig. 1: Histopathology: Effect of piracetam and vanadyl sulfate on experimentally induced cerebral ischemia in rats. 1. Control 2. Ischemia for $30 \mathrm{~min} 3$. Ischemia for $30 \mathrm{~min}$ followed by reperfusion for $60 \mathrm{~min} 4$. Piracetam $(600 \mathrm{mg} / \mathrm{kg}$,p. o)+ischemia for $30 \mathrm{~min}$ followed by reperfusion for $60 \mathrm{~min}$. 5 . Vanadyl Sulfate $(22.4 \mathrm{mg} / \mathrm{kg})+$ ischemia for $30 \mathrm{~min}$ followed by reperfusion for $60 \mathrm{~min} 6$. Piracetam $(600$ $\mathrm{mg} / \mathrm{kg}$. p. o) and Vanadyl sulfate $(22.4 \mathrm{mg} / \mathrm{kg}$. p. o)+ischemia for $30 \mathrm{~min}$ followed by reperfusion for $60 \mathrm{~min}$

\section{DISCUSSION}

In the present study, we evaluated the concomitant effect of piracetam and vanadyl sulfate on ischemia/reperfusion injury induced by bilateral carotid artery occlusion in rats, a global ischemia model in which ischemia/reperfusion injury induces the oxidative stress and causes neuronal damage in the brain. In accordance with previous reports bilateral carotid artery occlusion followed by reperfusion resulted in lesions such as cerebral congestion, cerebral edema and neutrophilic infiltration, decreased antioxidant levels and increased lipid peroxidation.

Cerebral ischemia is clinically a relevant problem occurring as damage to the brain following blood restoration after a critical period of cerebral artery occlusion. Oxygen is essential for aerobic life but is also a precursor to the formation of harmful ROS [22]. These radicals either directly or indirectly involved in various clinical disorders. Oxygen free radicals and lipid peroxidation are major factors in the etiology of stroke [23].
In the present study, rats induced with ischemia-reperfusion had a significant reduction in the endogenous antioxidants such as superoxide dismutase (SOD), catalase (CAT), glutathione (GSH), and Total thiol levels and showed significant increase LPO levels when compared to control group.

Normally there is a balance between the reactive oxygen species generation and the endogenous antioxidant systems, involving the cooperative action of SOD, CAT, and GSH. SOD, the primary line of defense against tissue damage caused by reactive oxygen species, catalyzes the dismutation of superoxide anion to hydrogen peroxide and prevents the formation of the hydroxyl radical. Catalase and GSH are generally regarded as the second line of defense by dismutating peroxide into water and molecular oxygen. GSH, an endogenous antioxidant found in all animals, can directly react with reactive oxygen species or act as a cofactor with the enzyme glutathione peroxidase to detoxify hydrogen peroxide and lipid peroxides in tissues [24]. Dysfunction of the glutathione system has been implicated in a number of neurodegenerative diseases and is a 
potential contributor to oxidative damage following temporary ischemia [25]. In the present study, pretreatment with piracetam and vanadyl sulfate showed a significant increase in GSH level and interestingly the level of GSH was further increased significantly when pretreated with a combination of piracetam and vanadyl sulfate. The CAT and SOD levels were increased in piracetam and vanadyl sulfate pretreated groups, and the group pretreated with piracetam and vanadyl sulfate in combination indicating the protection against oxidative stress.

During ischemia/reperfusion, sudden bursts of reactive oxygen species cannot be handled by the endogenous antioxidant systems and the accumulation of reactive oxygen species leads to cellular membrane, protein and DNA oxidative damage.

The lipid peroxide level is a measure of membrane damage as well as alteration in structure and function of the cellular membrane. ROS produces malondialdehyde (MDA), an end product of lipid peroxidation. MDA reacts with TBA and is, thus, estimated as TBARS [26]. The LPO level was significantly reduced in pretreated groups of piracetam, vanadyl sulfate and was significantly reduced in the group pretreated with both (piracetam and vanadyl sulfate) in combination indicating the protective effect of piracetam and vanadyl sulfate on oxidative damage.

In histopathological findings, piracetam pretreated group, and vanadyl sulfate pretreated groups showed a reduction in cerebral edema, congestion, and neutrophilic infiltration as compared to diseased control. The concomitant pretreated group showed more reduction in cerebral edema, congestion and neutrophilic infiltration as compared to ischemic reperfusion group representing the prevention of ischemia-reperfusion-induced tissue damage and inflammation.

Results of the present study showed that piracetam and vanadyl sulfate when administered in combination, reduced the oxidative stress and ROS-mediated tissue damage.

\section{CONCLUSION}

The findings of the present study suggest that pretreatment with piracetam and vanadyl sulfate in combination prevents the ischemia-reperfusion injury and prevented oxidative tissue damage as shown by decreased lipid peroxides, restored the antioxidant levels, histological changes such as inflammatory changes and edema. Further studies are warranted to pursue the interesting lead emerging from the present result to exploit the full therapeutic potential in a combination of piracetam and vanadyl sulfate.

\section{ACKNOWLEDGEMENT}

The authors are thankful to the Principal Dr. F. V. Manvi and Vice Principal Prof. A. D. Taranalli, KLEU'S College of Pharmacy, KLE University, Belgaum, Karnataka, India, for providing necessary facilities during the course of this study.

\section{CONFLICTS OF INTERESTS}

\section{Declared none}

\section{REFERENCES}

1. Wade SS, Johnson SC, Easton JD. Cerebrovascular disease. Principles of Internal Medicine. $16^{\text {th }}$ ed. McGraw-Hill; 2005. p. 372.

2. Warlow CP. Epidemiology of stroke. Lancet 1998;352:1-4.

3. Kaul S. Stroke in India: are we different from the world? J Neurol Sci 2007;2:158-64.

4. Sethi PK. Stroke incidence in India and management of ischemic stroke. Neuroscience 2002;2:139-42.

5. Tuhrim S. Management of stroke and transient ischemic attack. Mt Sinai J Med 2002;69:121-30.
6. Cheng YD, Khoury LA. Neuroprotection for ischemic stroke: two decades of success and failure. Am Soc Exp Neurother 2005;1:36-45.

7. Adamson J, Beswick A, Ebrahim S. Is stroke the most common cause of disability? J Stroke Cerebrovascular Diseases 2004;13:171-7.

8. Gorelick P. Racial differences in ischemic cerebrovascular diseases. J Stroke Cerebrovascular Diseases 1996;6:55-9.

9. Gupta Yk, Briyal S. Animal models of cerebral ischemia for evaluation of drugs. Indian J Physiol Pharmacol 2004;48:379-94.

10. Winblad B. Piracetam: a review of pharmacological properties and clinical uses. CNS Drug Rev 2005;11:169-82.

11. Tunali S, Yanardag. Effect of vanadyl sulfate on the status of lipid parameters and on stomach and spleen tissues of streptozotocin-induced diabetic rats. Pharmacol Res 2006;53:271-7.

12. Shioda N, Ishigami T, Han F, Moriguchi S, Shibuya M, Iwabuchi $\mathrm{Y}$, et al. Activation of phosphatidylinositol 3-kinase/ protein kinase $\mathrm{B}$ pathway by a vanadyl compound mediates its neuroprotective effect in mouse brain ischemia. J Neuropharmacol 2007;148:221-9.

13. Bhuiyan SMD, Shioda N, Fukunaga k. Targeting protein kinase B/Akt signaling with vanadium compounds for cardioprotection. Cardiovasc and Renal 2008;12:1217-27.

14. Zhi H, Liao Y, Zheng M, Zeng FD, Guo LJ. Piracetam improves cognitive deficits caused by chronic cerebral hypoperfusion in rats. Cell Mol Neurobiol 2008;28:613-27.

15. Llobet J, Domingo J. Acute toxicity of vanadium compounds in rats and mice. Toxicol Lett 1984;23:227-31.

16. Farbiszewski R, Bielawski K, Bielawska A, Sobaniec W. Spermine protects in vivo the antioxidant enzymes in transiently hypoperfused rat brain. Acta Neurobiol Exp 1995;55:253-8.

17. Prabhakar KR, Veerapur VP, Vipan PK, Priyadarsini KI, Rao BSS, Unnikrishnan MK. Evaluation and optimization of radioprotective activity of Coronopus didymus Linn. in irradiated mice. Int J Radiation Biol 2006;82:525-36.

18. Anuradha N, Chatkerjee IB. Assay of superoxide dismutase activity in animal tissues. J Biosci 1988;13:305-15.

19. Claiborne A. Catalase activity. In: Greenwald RA. Ed. CRC handbook of methods for oxygen radical research. CRC Press: Boca Raton, Florida, USA; 1995. p. 283-4.

20. Sedlak J, Lindsay RH. Estimation of total, protein-bound, and nonprotein sulfhydryl groups in tissue with Ellman's reagent. Anal Biochem 1968;25:192-205.

21. Lowry $\mathrm{OH}$, Rosebrough NJ, Fair AL, Randall RJ. Protein measurement with Folin phenol reagent. J Biol Chem 1951;193:265-75.

22. Leker RR, Shohami E. Cerebral ischemia and trauma-different etiologies yet similar mechanisms: neuroprotective opportunities. Brain Res Rev 2002;39:55-73.

23. Chandrashekhar VM, Ranpariya VL, Ganapaty S, Parashar A, Muchandi AA. Neuroprotective activity of Matricaria recutita Linn against the global model of ischemia in rats. J Ethnopharmacol 2010;127:645-51.

24. Wang Z, Liu T, Lu Gan, Wang T, Yuan X, Zhang B, et al. Shikonin protects mouse brain against cerebral ischemia/reperfusion injury through its antioxidant activity. Eur J Pharmacol 2010;643:211-7.

25. Dringer R. Metabolism and function of glutathione in brain. Prog Neurobiol 2000;62:649-71.

26. Dib M, Garrel C, Favier A, Robin V, Desnuelle C. Can malondialdehyde be used as a biological marker of progression in neurodegenerative disease? J Neurol 2002;249:367-74.

\section{How to cite this article}

- Banappa S Unger, Himasaila M. Pharmacological evaluation of piracetam and vanadyl sulfate on experimentally induced cerebral ischemia in rats. Int J Pharm Pharm Sci 2016;8(9):178-181. 